\author{
M. C. XMIЛЬ
}

\title{
ПРЕГРАВІДАРНА ПІДГОТОВКА ТА ВИБІР ОПТИМАЛЬНОГО ПРОТОКОЛУ КОНТРОЛЬОВАНОЇ ОВАРІАЛЬНОЇ СТИМУЛЯЦІї У ПАЦІЄНТОК ЗІ СИНДРОМОМ ПОЛІКІСТОЗНИХ ЯЄЧНИКІВ
}

\author{
Тернопільський національний медичний університет імені І. Я. Горбачевського МОЗ України, \\ м. Тернопіль, Україна \\ Медичний центр «Клініка профресора Стефана Хміля», м. Тернопіль, Україна
}

\begin{abstract}
Мета: підвищити ефективність лікування безпліддя шляхом оптимізації прегравідарної терапії та вибору оптимального протоколу стимуляції і тригера овуляції в пацієнток зі синдромом полікістозних яєчників (СПкЯ) у протоколах допоміжних репродуктивних технологій.

Матеріали і методи. Проведено клінічне обстеження 157 безплідних жінок зі синдромом полікістозних яєчників, яким запропоновано різні методи прегравідарної підготовки перед контрольованою оваріальною стимуляцією (КОС) у програмах екстракорпорального запліднення.

Результати. У дослідженні переважали жінки віком 30-34 років із тривалістю безпліддя до 5 років, яке у 82,8 \% пацієнток було первинним; серед супутніх патологій синдром полікістозних яєчників найчастіше поєднувався 3 чоловічим фрактором безпліддя у 52 (33,1\%) жінок.

Тривалість контрольованої стимуляції овуляції у пацієнток була приблизно однакова у всіх трьох групах. Сумарна доза гонадотропінів у пацієнток дослідних груп виявилася невеликою, проте найнижчі дози призначено жінкам зі синдромом полікістозних яєчників, яким здійснено прегравідарну підготовку вітамінним комплексом «FT-500 Plus» та вітаміном $\mathrm{D}_{3}$ у модисрікованому протоколі кOC із подвійним тригером овуляції. Так середня додаткова доза фолікулостимулювального гормону (ФСГ) у пацієнток першої групи склала $(675,25 \pm 85,2)$ МО, у другій $(750,45 \pm 90,8)$ МО, у третій - $(760,70 \pm 105,5)$ МO.

Одним із ускладнень у протоколах контрольованої оваріальної стимуляції в пацієнток із СПкя є синдром гіперстимуляції яєчників (СГЯ). Використання протоколів з антагоністами гонадотропін-рилізинг-гормону (ант-ГнРГ) та застосування рекомендованого нами в якості тригера овуляції агоніста ГнРГ «Диферелін» 0,2 мг/мл одноразово, в першій групі пацієнток протокол нами був модифікований, через 12 год додатково вводили його в дозі 0,1 мг/мл, що дозволяє значно знизити ризик СгЯ. В обстежених пацієнток першої групи СГЯ легкого ступеня виявлено в 1 (1,6 \%) пацієнтки, в другій - у 3 (6,3\%), а в третій контрольній групі - в 2 (4,3\%) пацієнток. Пацієнти не потребували госпіталізації, проходили лікування амбулаторно. На сьогодні заміна тригера овуляції на агоніст ГнРГ $€$ найефективнішим методом профрілактики Сгя.

Висновки. Використання прегравідарної підготовки в коротких модифікованих протоколах контрольованої оваріальної стимуляції зі застосуванням антагоністів гонадотропін-рилізинг-гормону та тригера агоніста «Диферелін» 0,2 мг/мл одноразово, в першій групі пацієнток протокол нами був модифікований, через 12 год додатково вводили його в дозі 0,1 мг/мл, що дозволяє значно знизити ризик Сгя та є безпечнішим, комфортнішим для пацієнтів за рахунок коротшої тривалості та нижчої вартості стимуляції овуляції.
\end{abstract}

КЛЮчОВІ СЛОВА: безпліддя; антагоніст гонадотропін-рилізинг-гормону; синдром полікістозних яєчників; FT-500 Plus; вітамін $\mathrm{D}_{3}$; фолієва кислота; допоміжні репродуктивні технології; екстракорпоральне запліднення.

На сьогодні безпліддя залишається однією із найактуальніших проблем у сучасному акушерстві, гінекології та репродуктології [5]. Найефрективнішим методом у лікуванні усіх фрорм як жіночого, так і чоловічого безпліддя $€$ допоміжні репродуктивні технології. Дана методика являє собою сукупність методів, які спрямовані на лікування безпліддя, за допомогою яких певні чи усі етапи від дозрівання, запліднення яйцеклітин та розвитку ембріонів до моменту перенесення їх у порожнину матки жінки відбуваються в умовах ембріологіï (in vitro), тобто поза організмом [2]. Серед жіночих форм безпліддя провідне місце посідає ендокринна форма, оскільки найчастіше

(с) М. С. Хміль, 2020 буває первинною та характеризується різноманіттям клінічних і лабораторних проявів. Спільною ознакою для усіх фрорм ендокринного безпліддя є ановуляція [4], що складає близько $40 \%$ усіх фрорм жіночого безпліддя [3]. Синдром полікістозних яєчників (СПКЯ) є найчастішою причиною ановуляторного безпліддя [1].

Це полісиндромне захворювання часто асоціюється з безпліддям, є найчастішою патологією у жінок репродуктивного віку як в Україні, так і за її межами. За даними літератури, СПкЯ діагностують майже у 50 \% жінок із порушеннями менструальної та овуляторної функцій та у 40 \% пацієнток, які мають ендокринне безпліддя. Частота сПкЯ у жінок репродуктивного віку становить 
6-20 \%. Варто зауважити, що понад 100 млн жінок 15-49-річного віку мають це захворювання $[1,6]$.

Отже, на сьогодні є велика кількість наукових публікацій щодо протоколів контрольованої стимуляції овуляції у пацієнток із синдромом полікістозних яєчників, однак наведені в них дані потребують систематизації, уточнення та оптимізації прегравідарної підготовки і вибору оптимального протоколу стимуляції та тригера овуляції, які забезпечили б якісний фолікулогенез та зменшили б ймовірність синдрому гіперстимуляції, чому власне і присвячена наша робота.

Мета дослідження: підвищити ефективність лікування безпліддя шляхом оптимізації прегравідарної терапії та вибору оптимального протоколу стимуляції і тригера овуляції в пацієнток із синдромом полікістозних яєчників у протоколах допоміжних репродуктивних технологій.

Матеріали і методи. Проведено клінічне обстеження 157 безплідних жінок із СПкя, яким запропоновано різні методи прегравідарної підготовки перед контрольованою оваріальною стимуляцією (КОС) у програмах екстракорпорального запліднення (ЕКЗ). Показаннями до лікування пацієнток зі синдромом полікістозних яєчників за допомогою допоміжних репродуктивних технологій (ДРТ) було поєднання СПКя та трубноперитонеального фрактора безпліддя і/або порушення сперматогенезу в чоловіків, відсутність вагітності після 3-5 спроб індукції овуляції кломіфрен цитратом.

Залежно від причин безпліддя та методу лікування хворих поділено на три клінічні групи.

Першу клінічну групу (40,1 \%) склали 63 жінки з безпліддям на фроні СПКЯ, які перед проведенням контрольованої стимуляції овуляції отримували комбіновану терапію вітамінного комплексу «FT-500 Plus» по одному саше один раз на добу впродовж 2-3 місяців та препарат вітаміну $\mathrm{D}_{3}$ «Аквадетрим» у середньотерапевтичних дозах по 2 краплі 2-3 рази на добу протягом 2-3 місяців.

Друга клінічна група (30,6 \%) склала 48 безплідних жінок на тлі СПКЯ, які щодня протягом 2-3 місяців перед та під час контрольованої стимуляції суперовуляції до пункції фролікулів із аспірацією ооцитів отримували фолієву кислоту (400 мкг).

Третю клінічну групу (29,3 \%) склали 46 жінок із безпліддям на тлі СПКЯ, яким не проводили прегравідарну підготовку.

У трьох досліджуваних групах пацієнткам контрольовану оваріальну стимуляцію здійснювали за допомогою рекомбінантного гонадотропіну коріфолітропіну-альфра - «ЕЛОНВА» за коротким протоколом із використанням антагоніста ГнРГ. На 5-7 дні стимуляції залежно від стартової відповіді яєчників на стимуляцію, коли розміри фолікулів досягали не менше 14-15 мм, призначали щоденно антагоніст гонадотропін-рилізинг гормон (ГнРГ) «Оргалутран» по 0,25 мг підшкірно. На 8 день після введення «ЕЛОНВА» продовжували стимуляцію суперовуляції рекомбінантним ФСГ «Пурегон» до кінцевого дозрівання ооцитів (розміри 3 фролікулів $\geq 18$ мм), в якості тригера використовували агоніст ГнРГ «Диферелін» 0,2 мг/мл одноразово, в першій групі пацієнток протокол був нами модифікований, через 12 год додатково вводили його в дозі 0,1 мг/мл.

В умовах малої операційної під контролем трансвагінального датчика проводили пункцію фолікулів та аспірацію фролікулярної рідини голками «СООК» (США) через 35-36 год після введення тригера овуляції. Запліднення яйцеклітин та культивування ембріонів із подальшою вітрифрікацією на 5 добу (стадія бластоцисти) здійснювали в умовах IVF-лабораторії.

Перед застосуванням методів дРТ у подружніх пар проводили збір даних щодо попереднього обстеження та лікування 3 наступним обов'язковим стандартним протоколом обстеження (ОСПО). В обстежуваних жінок аналізували особливості встановлення і подальшого розвитку репродуктивної функції, у зв'язку з цим проводили вивчення преморбідного фону, який сприяє проявам неспроможності репродуктивної системи.

Відміну перенесення ембріонів 3 наступною кріоконсервацією проводили у всіх трьох групах (157 пацієнток). Через 1-3 місяці після завершення програм ЕКЗ пацієнткам виконували перенесення кріоконсервованих ембріонів за стандартною методикою.

Статистичний аналіз результатів дослідження здійснювали за допомогою комп'ютерного забезпечення з використанням програм «Microsoft Office Excell» та «Statistica».

Результати дослідження та їх обговорення. При аналізі анамнестичних даних виявлено, що вік обстежених пацієнток коливався від 25 до 39 років, що відповідає найбільш активному репродуктивному періоду жінки. Результати клінічного обстеження пацієнток показали однаковий поділ жінок за віком у дослідних групах. Середній вік пацієнток в першій групі склав $(31,47 \pm 4,1)$ року,

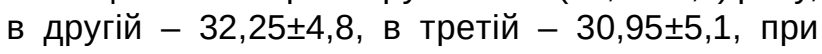
цьому найбільше у клініку репродуктології звернулося осіб віком 30-34 роки: у першій групі 31 (49,21\%), в другій - 25 (52,08\%), у третій 23 (50,0 \%) (табл. 1).

У першій групі більшість жінок були міськими жительками, а саме 40 (63,49\%) пацієнток, в другій групі цей показник склав 29 (60,42 \%) пацієнток, у третій - 25 (54,35 \%), а сільські жительки склали: 23 (36,51 \%), 19 (39,58 \%), 21 (45,65 \%) відповідно за групами (рис. 1). 
Таблиця 1. Поділ пацієнток за віком

\begin{tabular}{|c|c|c|c|c|c|c|}
\hline \multirow[t]{2}{*}{$\begin{array}{l}\text { Вікові } \\
\text { групи }\end{array}$} & \multicolumn{2}{|c|}{$\begin{array}{c}\text { I група (n=63) модиорікована } \\
\text { схема КОс }\end{array}$} & \multicolumn{2}{|c|}{$\begin{array}{c}\text { II група }(n=48) \text { стандартна схема } \\
\text { КОс }\end{array}$} & \multicolumn{2}{|c|}{ III група (n=46) контрольна } \\
\hline & абс. & \% (95 \% ДІ) & абс. & \% (95 \% ДІ) & абс. & \% (95 \% ДІ) \\
\hline $\begin{array}{l}25-29 \\
\text { років }\end{array}$ & 22 & $\begin{array}{c}34,92 \\
(24,33-47,25)\end{array}$ & 15 & $\begin{array}{c}31,25 \\
(13,31-36,54)\end{array}$ & 17 & $\begin{array}{c}36,96 \\
(12,26-35,57)\end{array}$ \\
\hline $\begin{array}{c}\text { 30-34 } \\
\text { роки }\end{array}$ & 31 & $\begin{array}{c}49,21 \\
(37,27-61,24)\end{array}$ & 25 & $\begin{array}{c}52,08 \\
(40,29-67,43)\end{array}$ & 23 & $\begin{array}{c}50,0 \\
(38,13-65,87)\end{array}$ \\
\hline $\begin{array}{l}35-39 \\
\text { років }\end{array}$ & 10 & $\begin{array}{c}15,87 \\
(8,85-26,81)\end{array}$ & 8 & $\begin{array}{c}16,67 \\
(13,31-36,54)\end{array}$ & 6 & $\begin{array}{c}13,04 \\
(15,60-40,26)\end{array}$ \\
\hline
\end{tabular}

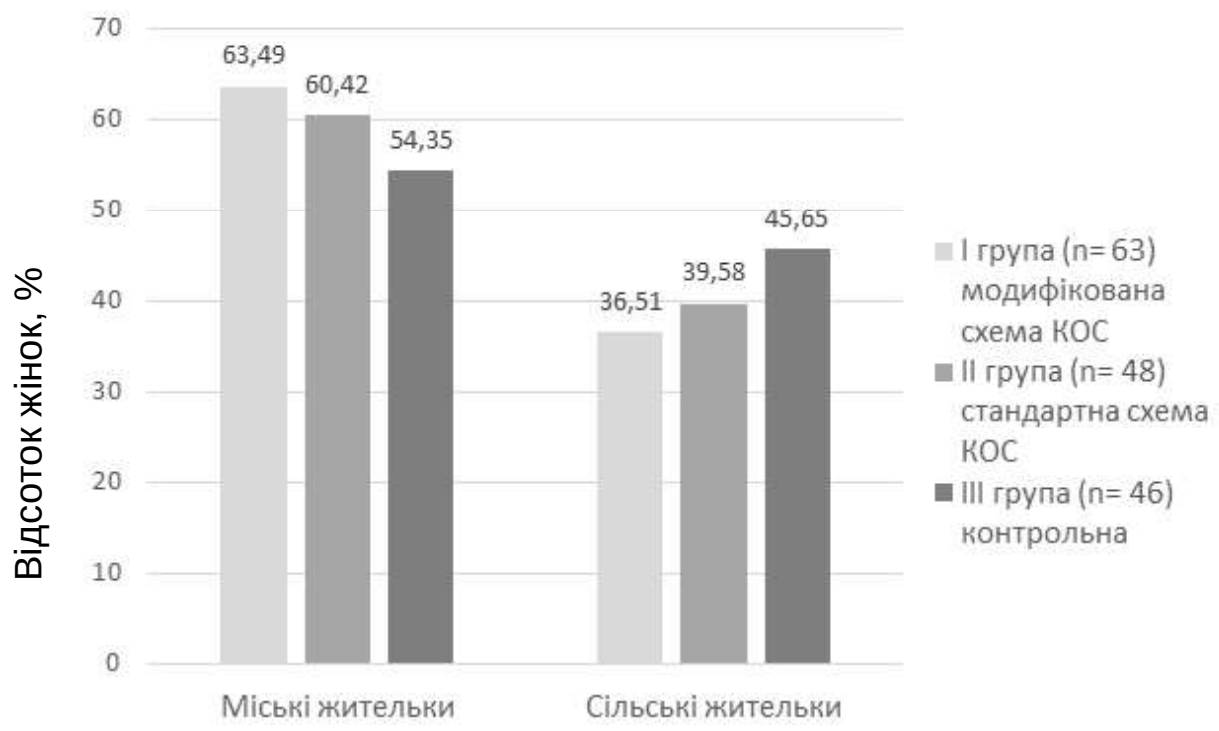

Рuc. 1. Поділ жінок за місцем проживання.

Серед 63 жінок першої групи, включених у дослідження, середній термін безпліддя до 5 років виявлено у 33 (52,3\%) осіб, 6-9 років - 19 (30,1\%) і понад 10 років - у 11 (17,6 \%) жінок (рис. 2). Серед 48 жінок другої групи на відсутність вагітності до 5 років скаржилося 28 (58,3 \%) осіб, 6-9 років - $13(27,08 \%)$ пацієнток та більше 10 років - $7(14,62 \%)$ жінок, у третій контрольній групі (46 жінок) тривалість безпліддя до 5 років склала 21 (46,6 \%) випадок, 6-9 років - 16 (34,7 \%) випадків і понад 10 років - 9 (19,7 \%). Показники тривалості безпліддя у пацієнток всіх трьох груп порівняно дещо відрізнялися за структурою.

Аналізуючи пацієнток за типом безпліддя, переважали жінки з первинним у всіх дослідних групах (82,8 проти 17,2 \% з вторинним безпліддям). При цьому як первинне, так і вторинне безпліддя мали місце в практично однаковій кількості жінок різних дослідних груп (табл. 2).

Аналіз структури супутніх захворювань репродуктивної системи показав, що в усіх групах вірогідно не відрізняється частота поєднання 3 чоловічим фрактором безпліддя, трубно-перитонеальним та комбінованим чоловічим фрактором + трубно-перитонеальним безпліддям. Варто також зазначити, що найчастіше у пацієнток всіх груп діагностували СПКЯ у поєднанні з чоловічим фрактором безпліддя у 52 (33,1 \%) жінок.

Проведений нами аналіз анамнестичних даних пацієнток дозволяє обґрунтовано припускати, що групи порівняння були практично ідентичні за такими чинниками, як вік, тривалість і тип безпліддя.

Комплексна оцінка клінічних та анамнестичних даних жінок із верифрікованим діагнозом «жіноче безпліддя, синдром полікістозних яєчників», які були включені у дослідження, свідчить про переважання жінок віком 30-34 років із тривалістю безпліддя до 5 років, яке у 82,8 \% пацієнток було первинним; серед супутніх патологій спкя найчастіше поєднувався з чоловічим фрактором безпліддя у $52(33,1 \%)$ жінок.

\section{Таблиця 2. Поділ пацієнток за типом безпліддя}

\begin{tabular}{|c|c|c|c|c|c|c|}
\hline \multirow{2}{*}{ Тип безпліддя } & \multicolumn{2}{|c|}{$\begin{array}{c}\text { I група }(\mathrm{n}=63) \\
\text { модисрікована схема КОс }\end{array}$} & \multicolumn{2}{|c|}{$\begin{array}{c}\text { II група }(\mathrm{n}=48) \\
\text { стандартна схема КОС }\end{array}$} & \multicolumn{2}{c|}{$\begin{array}{c}\text { III група }(\mathrm{n}=46) \\
\text { контрольна }\end{array}$} \\
\cline { 2 - 7 } & абс. & $\%$ & абс. & $\%$ & абс. & \% \\
\hline Первинне & 54 & 85,7 & 42 & 87,5 & 36 & 78,3 \\
\hline Вторинне & 9 & 14,3 & 6 & 12,5 & 10 & 21,7 \\
\hline
\end{tabular}




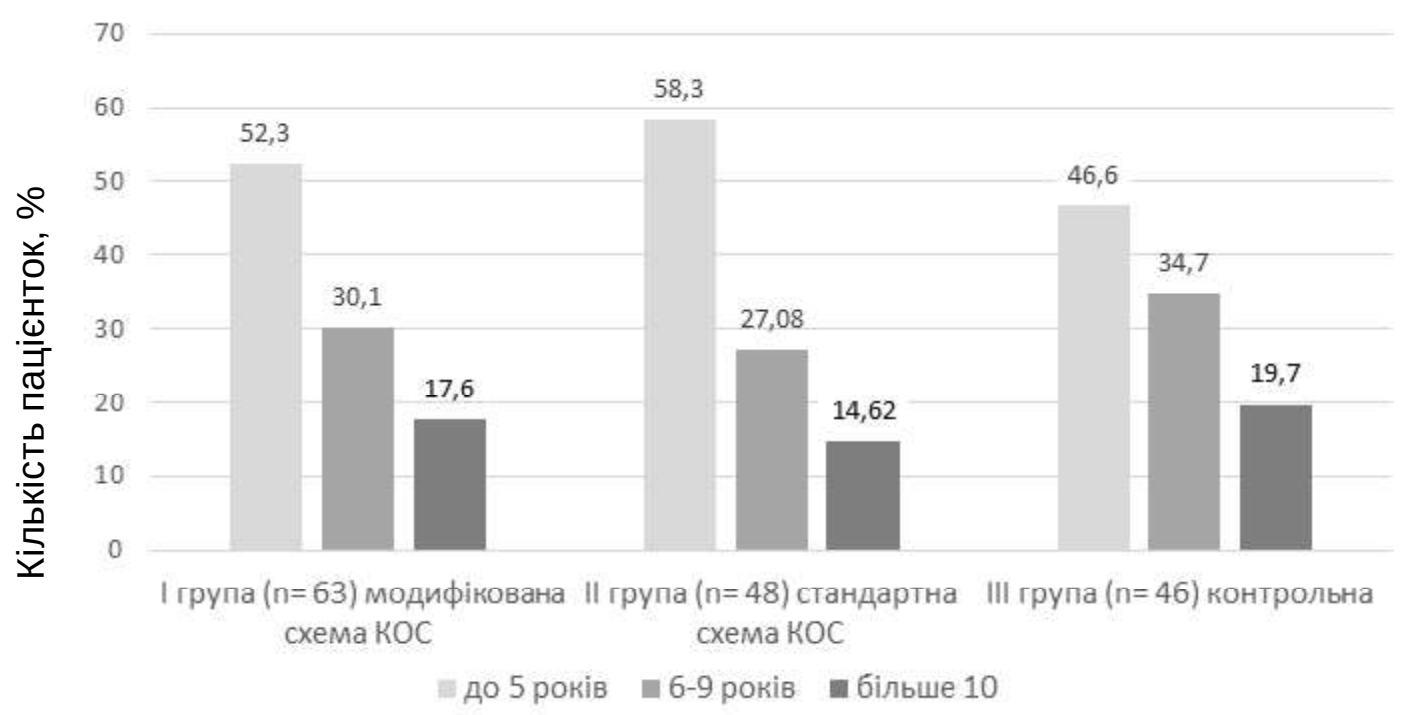

Рuc. 2. Поділ жінок за терміном безпліддя.

Проведений аналіз свідчить про однотипність дослідних груп.

При оцінці результатів індукції суперовуляції встановлено, що тривалість стимуляції у пацієнток дослідних груп, доза та кратність введення препаратів визначалася за допомогою ультразвукового та гормонального моніторингу і вірогідно не відрізнялася від контролю. Аналізуючи тривалість контрольованої стимуляції овуляції у пацієнток встановлено, що приблизно однакова ії тривалість була у всіх трьох групах, а саме: у першій групі - $(10,15 \pm 0,18)$ дня, у другій групі $(10,90 \pm 0,20)$ дня та у третій групі пацієнток $(10,75 \pm 0,24)$ дня. Сумарна доза гонадотропінів у пацієнток дослідних груп виявилася невеликою, проте найнижчі дози призначено жінкам зі СПКЯ, яким здійснено прегравідарну підготовку вітамінним комплексом «FT-500 Plus» та вітаміном $\mathrm{D}_{3}$ в модифрікованому протоколі КОС $з$ подвійним тригером овуляції. Так середня додаткова доза ФСГ у пацієнток першої групи склала $(675,25 \pm 85,2)$ MO, у другій - $(750,45 \pm 90,8)$ MO, у третій - $(760,70 \pm 105,5)$ МО.

Одним із ускладнень у протоколах контрольованої оваріальної стимуляції в пацієнток із СПКЯ є синдром гіперстимуляції яєчників. Використання протоколів 3 антагоністами гонадотропін-рилізинг-гормону та застосування рекомендованого нами в якості тригера овуляції агоніста ГнРГ «Диферелін» 0,2 мг/мл одноразово, в першій групі пацієнток протокол був нами модифрікований, через 12 год додатково вводили його в дозі 0,1 мг/мл, що дозволяє значно знизити ризик СГЯ. В обстежених нами пацієнток першої групи СгЯ легкого ступеня виявлено у 1 (1,6 \%) пацієнтки, в другій - у 3 (6,3\%), а в третій контрольній групі - у 2 (4,3 \%) пацієнток. Пацієнти не потребували госпіталізації, проходили лікування амбулаторно. На сьогодні заміна тригера овуляції на агоніст ГнРГ є найесрективнішим методом профрілактики СГЯ.

\section{Висновки}

Використання прегравідарної підготовки в коротких модифрікованих протоколах контрольованої оваріальної стимуляції зі застосуванням антагоністів гонадотропін-рилізинг-гормону та тригера агоніста «Диферелін» 0,2 мг/мл одноразово, в першій групі пацієнток протокол був нами модифікований, через 12 год додатково вводили його в дозі 0,1 мг/мл, що дозволяє значно знизити ризик СГЯ та $є$ безпечнішим, комсрортнішим для пацієнтів за рахунок коротшої тривалості та нижчої вартості стимуляції овуляції.

Перспективи подальших досліджень. Враховуючи, що контрольована оваріальна стимуляція у пацієнток із СПкЯ є фрактором ризику розвитку ускладнень та зниження якості яйцеклітин, необхідно розробити діагностично-лікувальний алгоритм з урахуванням всіх ланок патогенезу даної проблеми, що дасть змогу підвищити ефективність досягнення вагітності у пацієнток.

\section{Список літератури}

1. Гуриев Т. Д. Синдром поликистозных яичников / Т. Д. Гуриев // Акушерство, гинекология и репродукция. - 2010. № 4 (2). - С. 10-15.

2. Капустін Е. В. Місце та роль допоміжних репродуктивних технологій (ДРТ) у лікуванні непліддя та збереженні фрертильності / Е. В. Капустін, Г. Й. Геревич // Акушерство. Гінекологія. Генетика. - 2016. - Т. 2, № 2. - С. 30-33.

3. Манушарова Р. А. Бесплодный брак / Р. А. Манушарова // Эффективная фрармакотерапия. Эндокринология. 2014. - № 1 (9). - С. 34-39.

4. Тюрина Н. А. Причины женского бесплодия / Н. А. Тюрина, Ю. Ф. Сайфретдинова // Огарёв-online. - 2014. № 12. - C. 1-5. 
5. Юзько О. М. Подолання безпліддя за допомогою репродуктивних технологій // О. М. Юзько, Т. А. Юзько // Медичні аспекти здоров'я жінки. - 2009. - № 3 (20). - С. 20.

6. Natural molecules for the therapy of hyperandrogenism and metabolic disorders in PCOS / V. Capelli, M. C. Musacchio, A. Bulfoni [et al.] // European Review for Medical and Pharmacological Sciences. - 2017. - Vol. 21, No. 2. - P. 15-29.

\section{References}

1. Guriyev, T.D. (2010). Sindrom polikistoznykh yaichnikov [Polycystic ovary syndrome]. Akusherstvo, ginekologiya $i$ reproduktsiya - Obstetrics, Gynecology and Reproduction, 4 (2), 10-15 [in Russian].

2. Kapustin, E.V., \& Herevych, H.Y. (2016). Mistse ta rol dopomizhnykh reproduktyvnykh tekhnolohii (DRT) u likuvanni nepliddia ta zberezhenni fertylnosti [The place and role of assisted reproductive technologies (ART) in the treatment of infertility and fertility]. Akusherstvo. Hinekolohiia. Henetyka - Obstetrics. Gynecology. Genetics, 2 (2), $30-33$ [in Ukrainian]. 3. Manusharova, R.A. (2014). Besplodnyy brak. Effektivnaya farmakoterapiya [Barren marriage. Effective pharmacotherapy]. Endokrinologiya - Endocrinology, 1 (9), 34-39 [in Russian].

4. Tyurina, N.A., \& Sayfetdinova, Yu. F. (2014). Prichiny zhenskogo besplodiya [Causes of female infertility]. Ogarovonline - Ogarev-online, 2, 1-5 [in Russian].

5. Yuzko, O.M., \& Yuzko, T.A. (2009). Podolannia bezpliddia za dopomohoiu reproduktyvnykh tekhnolohii [Overcoming infertility with the help of reproductive technologies]. Medychni aspekty zdorovia zhinky - Medical Aspects of Women's Health, 3 (20), 20 [in Ukrainian].

6. Capelli, V., Musacchio, M.C., \& Bulfoni, A. (2017). Natural molecules for the therapy of hyperandrogenism and metabolic disorders in PCOS. European Review for Medical and Pharmacological Sciences, 21 (2), 15-29.

\section{PRETREATMENT AND SELECTION OF THE OPTIMAL PROTOCOL OF CONTROLLED OVARY STIMULATION IN PATIENTS WITH POLYCYSTIC OVARY SYNDROME}

M. S. Khmil

I. Horbachevsky Ternopil National Medical University, Ternopil, Ukraine

Medical Center "Clinic of Professor Stefan Khmil", Ternopil, Ukraine

Purpose: to improve the effectiveness of infertility treatment by optimizing pretreatment program and selecting the optimal stimulation protocol and ovulation trigger in patients with polycystic ovary syndrome in the protocols of assisted reproductive technologies.

Materials and Methods. A clinical examination of 157 infertile women with PCOS was performed, who were offered various pretreatment methods before controlled ovarian stimulation (COS) in in vitro fertilization (IVF) programs.

Results. The study was dominated by women aged 30-34 years with a duration of infertility up to 5 years, which in $82.8 \%$ of patients was primary; among concomitant pathologies, PCOS was most often combined with the male factor in $52(33.1 \%)$ women.

The duration of controlled ovulation stimulation in patients was approximately the same in all three groups. The total dose of gonadotropins in patients of the experimental groups was small, but the lowest doses were prescribed to women with PCOS, who underwent IVF protocol pretreatment with vitamin complex FT500 Plus and vitamin $\mathrm{D}_{3}$ in a modified IVF protocol with a double ovulation trigger. Thus, the average additional dose of follicle stimulating hormone (FSH) in patients of the first group was (675. 25 \pm 85.2$) \mathrm{IU}$, in the second $-(750.45 \pm 90.8) \mathrm{IU}$, in the third - (760.70 \pm 105.5$)$ IU.

One of the complications in controlled ovarian stimulation protocols in patients with PCOS is ovarian hyperstimulation syndrome. Use of protocols with gonadotropin-releasing hormone antagonists (ant-GnRH) and use of the recommended $\mathrm{GnRH}$ agonist (Diferelin) $0.2 \mathrm{mg} / \mathrm{ml}$ as an ovulation trigger, $0.1 \mathrm{mg} / \mathrm{ml}$ after $12 \mathrm{~h}$ which significantly reduces the risk of OHSS. In the examined patients of the first group mild OHSS was diagnosed in $1(1.6 \%)$ persons, in the second $-3(6.3 \%)$, and in the third control group $-2(4.3 \%)$ patients. Patients did not require hospitalization, were treated on an outpatient basis. To date, replacement of the ovulation trigger with a $\mathrm{GnRH}$ agonist is the most effective method of OHSS prevention.

Conclusions. The use of pretreatment program in short modified protocols of controlled ovarian stimulation using gonadotropin-releasing hormone antagonists $(\mathrm{GnRH})$ and agonist trigger (Diferelin) according to the scheme $0.2 \mathrm{mg} / \mathrm{ml}$ after $12 \mathrm{~h} 0.1 \mathrm{mg} / \mathrm{ml}$ can significantly reduce the risk of OHSS, which is safer and more comfortable for patients due to the shorter duration and lower cost of ovulation stimulation.

KEY WORDS: infertility; GnRH antagonist; polycystic ovary syndrome; FT500 Plus; vitamin $\mathrm{D}_{3}$; folic acid; assisted reproductive technologies; in vitro fertilization.

Рукопис надійшов до редакції 04.06.2020 p.

\section{Відомості про автора:}

Хміль Марія Стефанівна - асистент кафедри акушерства та гінекології № 1 Тернопільського національного медичного університету імені І. Я. Горбачевського МО3 України. Медичний директор Медичного центру «Клініка профресора Стефана Хміля»; тел.: +38(067) 846-35-34. 